\title{
O SUBGRUPO ITARARÉ (PERMOCARBONÍFERO) NA REGIÃO DO MÉDIO TIETÊ, ESTADO DE SÃO PAULO*
}

\author{
SETEMBRINO PETRI** \& FERNANDO A. PIRES**
}

\begin{abstract}
THE HARARE SUBGROUP (CARBONIFEROUS/PERMIAN) IN THE MIDDLE TIETE VALLEY, STATE OF SÃO PAULO. BRAZIL. The sediments of the Permo-Carboniferous Itararé Subgroup of the Tietê river middle valley, State of Sao Paulo, Brazil were studied in outcrops and cores from wells drilled up to $310 \mathrm{~m}$ for groundwater, in order to get a general picture of their stratigraphic relationships. The Subgroup in this valley may be subdivided into the Itu and Capivari, testifying a transgressive cycle starting with the non-marine Itu Formation, and followed by the marine Capivari Formation. The marine transgression maximum resulted in the deposits of the Tatui Formation belonging to the Permian Guatá Subgroup. A paleogeographic model is developed for the Capivari Formation in the Tietê river middle valley, on basis of outcrops and eight wells throughly cored down to $310 \mathrm{~m}$. A continuous offshore marine environment occupied the areas located south and west of Capivari and Rafard (SP) towns. Submarine debris flows, coming from northeast, encroached upon this offshore environment in at least two channels, one of them reaching present day urban Capivari.
\end{abstract}

Keywords: Permocarboniferous, Itararé Subgroup, Middle Tietê River, State of São Paulo, Brazil.

\begin{abstract}
RESUMO Os sedimentos dp Subgrupo Itararé, de idade permocarbonífera, que se distribuem na região do médio Tietê, Estado de São Paulo, Brasil, foram estudados em afloramentos e testemunhos de poços para água subterrânea. De acordo com as informações obtidas, as Formações Itu, Capivari e Tatuí foram consideradas constituintes de uma seqüência retrogradacional, ou seja, depositadas durante um episódio trangressivo. Propõe-se, aqui, um modelo paleogeográfico para todo o vale, com pormenores para a região Capivari-Rafard. Condições marinhas de costa afora ocorreriam em áreas localizadas ao sul e oeste, fluxos de detritos, avançariam sobre a costa afora, vindos de nordeste. Pelo menos dois destes fluxos foram reconhecidos, o maior alcançando o sítio urbano de Capivari.
\end{abstract}

Palavras-chaves: Subgrupo Itararé, Permocarbonífero, Vale Médio Tietê, São Paulo, Brasil.

INTRODUÇÃO De 1985 a 1990, o Instituto Geológico da Secretaria de Estado do Meio Ambiente (IG-SMA) perfurou 13 poços para água subterrânea, com testemunhagem completa, na região de afloramentos do Subgrupo Itararé no vale do médio Tietê.

A profundidade máxima atingida por estes poços foi de $310 \mathrm{~m}$ e a mínima $80 \mathrm{~m}$. Destes 13 poços, seis estão localizados em tomo da conurbação Capivari-Rafard. Para esta região foram considerados, ainda, mais dois poços perfurados pelo IG-SMA antes de 1985, dos quais se tem a disposição dados sobre a perfilagem litológica.

Às ilustrações dos perfis litológicos condensados dos poços perfurados pelo IG-SMA na região de Capivari-Rafard podem ser encontradas em Petri (1992). Aqui só estão reproduzidos os perfis dos poços C-IG/90 e J-IG/86, o primeiro por conter o holoestratótipo aqui proposto para a Formação Capivari e o segundo por conter os sedimentos do topo da Formação Capivari e inclusive depósitos da Formação Tatuí.

Os oito poços localizados em tomo da conurbação Capivari-Rafard, associados a um afloramento de siltito com fósseis marinhos situado a cerca de $6 \mathrm{~km}$ a SE da cidade de Capivari, forneceram informações que permitiram que se propusesse um modelo de relações paleoambientais para esta região, em um certo tempo de deposição de sedimentos do Itararé (Fig. 7)

O modelo referido acima é extrapolado para um contexto mais amplo, envolvendo as unidades litoestratigráficas do subgrupo tais como aparecem em toda a região do médio Tietê.

LITOESTRATIGRAFIA A litoestratigrafia aqui proposta se aplica à região do médip Tietê e arredores. Faltam dados para que ela, eventualmente, possa ser estendida a outras áreas.
Andrade \& Soares (1971) e Soares \& Landim (1973) notaram a predominância de certas litologias do Subgrupo Itararé no Estado de São Paulo, em determinados pacotes. Tendo esta observação em mente, Soares et al. (1977) reconheceram, na região do médio Tietê, três pacotes que estariam se superpondo estratigraficamente, o inferior, com folhelhos rítmicos, ritmitos, diamictitos, arenitos, arenitos conglomerates e conglomerados, o médio com siltito, ritmito e diamictito e o superior essencialmente constituído de arenito ocorrendo, também, diamictito. Considerando estes pacotes como membros, utilizaram os termos Itu, Capivari e Tietê, até que novos dados permitissem seu mapeamento e elevação à categoria de formação.

No mapa geológico da região do baixo Capivari, escala 1:50.000, elaborado em 1985 pela UNESP e DAEE, foram separados, sem denominação, um Itararé médio e um superior.

Maniakas (1986) reproduziu mapa geológico de parte desta área, chamando o Itararé médio de Membro Capivari e o superior de Membro Tietê. Stevaux et al (1987), em estudo sobre os sistemas deposicionais do subgrupo na região do baixo Capivari, publicaram, como figura 2, uma subdivisão litoestratigráfica do subgrupo, considerando Itu, Capivari e Tietê na categoria de formação.

Esta subdivisão tripartite do Itararé paulista, esboçada com dados de afloramentos e de poços rasos na área, é, também, exposta por França (1987) e França \& Potter (1988), com base em poços profundos. Ao contrário dos autores anteriores, estes admitiram que as ocorrências situadas no depocentro da bacia do Paraná seriam as mais antigas e, gradativamente, a área de sedimentação seria ampliada para a borda e, portanto, os sedimentos da borda seriam os mais novos.

\footnotetext{
* Trabalho desenvolvido com financiamento da FAPESP

** Instituto Geológico, Secretaria do Meio Ambiente do Estado de São Paulo, Avenida Miguel Stéfano, 3900, Caixa Postal 8772, CEP 04301-903, Fax (011) 2768572, São Paulo, SP, Brasil
} 
Certamente, a maior subsidência da arca central da bacia deve ter propiciado acúmulo de sedimentos da base da seqüência. Lateralmente ao depocentro, deve ter havido alguma sedimentação. Os sedimentos da borda devem ter sido parcialmente destruídos por erosão subseqüente; acredita-se aqui que algum registro deve ter sido preservado em áreas deprimidas. Assim, Lima et al. (1983) dataram os fósseis marinhos de Araçoiaba, contidos em sedimentos próximos à borda da bacia, na região centro-leste do Estado de São Paulo, chegando à idade Pré-G, embora ainda do Stephaniano, do Neocarbonífero. "Varvitos" da região de Itu, por outro lado, pouco mais ao norte, ainda na borda centro-leste, teriam idade I-1, isto é, base do Kunguriano, Eopermiano (Dino et al 1987).

França (1987) levantou, implicitamente, a possibilidade de que sua Formação Lagoa Azul, a mais antiga, pudesse aparecer em afloramentos, que seriam tectonicamente controlados por lineamentos estruturais. É o que se deduz da observação de seus mapas de trend da Formação Lagoa Azul e de resíduos, mostrando influência de lineamentos estruturais na distribuição desta formação. Segundo este autor, o controle tectônico se atenuaria para o topo do subgrupo.

Soares et al (1977) chamaram a atenção para recorrências de litologias durante a deposição do subgrupo, o que dificultaria o reconhecimento das unidades em afloramentos isolados. A razão das recorrências é que as referidas unidades representam complexos ambientais que recorrem no tempo. O chamado "pacote inferior" de Soares et al (1977) é o reflexo de condições marginais, com maior proximidade das áreas emersas que bordejavam a bacia e, portanto, com maior influência de feições erosivas do embasamento, de topografia relativamente acidentada em vales e elevações. É este o domínio das moutonnées, conhecidas em Salto e dos pavimentes estriados de Salto de Pirapora e de Pilar do Sul. Este pacote foi aqui designado de Formação Itu.

FORMAÇÃO ITU Na região de Itu, abaixo do espesso "varvito clássico de Itu", ocorrem elásticos grossos, arenitos e diamictitos arenosos, com espessura que pode atingir $210 \mathrm{~m}$, como no poço It-IG/85 (Petri 1986), ou eventualmente mais.
A Formação Itu foi proposta por Barbosa e Almeida (1949) mas com uma conceituação diferente da aqui considerada. Na nossa conceituação, esta formação corresponde, em linhas gerais, à adotada por Stevaux et al (1987). A evolução do conceito desta formação está sintetizada na tabela 1 .

Como mostrou Stevaux et al (1987), comentando seções geológicas elaboradas por Mezzalira (1969), com base em poços perfurados pelo Instituto Geológico, em Schincariol, na região de Itu, o espesso ritmito clássico de Itu (Petri 1985, 1986), representa um marco transgressivo (Fig. 2). Este marco indicaria a base da Formação Capivari, a qual é aqui considerada como representativa de um mar proveniente de sudoeste, sempre presente durante o resto da deposição do Itararé e que, embora com flutuações regressivas causadas por construções deltaicas, avançaria, gradativamente, para nordeste. A passagem do mar Capivari para o mar Tatuí seria contínua.

A Seção do poço It-IG/85 (Petri 1986), da sua base, em contato com o embasamento cristalino, a $261,5 \mathrm{~m}$ de profundidade, até $51 \mathrm{~m}$, quando se inicia o espesso 'Varvito clássico de Itu", foi selecionada para holoestratótipo da Formação Itu. $\mathrm{Na}$ base deste poço ocorre um diamictito maciço, de matriz arenosa, com seixos esparsos de litologias variadas, passando, acima, através de granodecrescência ascendente, para arenitos predominantemente muitos finos, mal selecionados, contendo raros níveis de siltitos e delgadas intercalações de arenito médio a fino. Outros níveis delgados de diamictitos arenosos maciços ocorrem acima, intercalados no arenito muito fino, mal selecionado, com películas síltico-argilosas esporádicas e de distribuição irregular. Diastemas, pequenas perturbações, dobras e falhas irregulares, ocorrem com relativa freqüencia.

As seções dos poços de Schincariol, município de Itu, elaboradas por Mezzalira (1969) através de quatro poços perfurados pelo Instituto Geológico, em uma distância dê 250 m (Fig. 2), exemplificam as características da Formação Itu e de seu contato com a Formação Capivari.

A seção do poço de Salto da Pirapora, descrita por Mezzalira (1980) exibe $70 \mathrm{~m}$ de sedimentos interpretados como da Formação Itu, em contato com o embasamento cristalino também

Tabela l - Evolução do conceito da Formação Itu. 1. O tilito Elias Fausto foi desmembrado da Formação Itu por Barbosa e Gomes. 2. Síntese dos dados de Andrade e Soares (1971) e Soares e Landim (1973). 3. Souza (1986) não menciona explicitamente a Formação Itu. Ele a chama "Unidade Basal I". Significado das abreviações: til Tilito; suces. sucessão; espes. espessa; aren arenito ou arenoso; interc. intercalaçôes; folhfolhelho; local/ localmente; varv. varvito; congl conglomerado ou conglomeráticos; sed. sedimentos; pred. predominantemente; diamict. diamictito; ntm. ritmitos; delg. delgados; calc. calcário; veg. vegetais; estrat. $X$. estratificação cruzada; p. para; c. com; granod. ascend, granodecrescência ascendente; desc. descontínuos; Argil argilito Table 1 - The Itu Formation as understood by several authors. 1. Elias Fausto Tillite not included in the Itu Formation by Barbosa and Gomes. 2. Data compiled from Andrade and Soares (1971) and Soares and Landim (1973). 3. Souza (1986) does not mention Itu Formation but "Unidade basal I". Meaning of the abridgments: til. tillite; suces. sucession; espes. rickness; aren. sandstone or sandy; interc. intercalations; folh. shale; local/locally; varv. varvite; congl. conglomerate or conglomeratic; sed. sedimente; pred. predominantly; diamict diamictite; ritm. rythmites; delg. thin; calc. limestone; veg. plants; estrat x. crossbed; p. to; c.with; granod. ascend, fining upward; desc. descontinuous, argil, argillite

\begin{tabular}{|c|c|c|c|c|c|}
\hline Barbosa \& Almeida & $\begin{array}{c}\text { Barbosa o Comes } \\
1958 \text { (1) }\end{array}$ & $\begin{array}{c}\text { Soares et al. } \\
1977(2)\end{array}$ & $\begin{array}{l}\text { Souza } \\
1986(3)\end{array}$ & $\begin{array}{c}\text { Stevaux et al. } \\
1987\end{array}$ & Presente proposta \\
\hline $\begin{array}{l}\text { D - Til. Elias Fausto } \\
\text { C - Suces. espes. de } \\
\text { aren. e inter. locais } \\
\text { de folh. local } \\
\text { varvitos Carvaio de } \\
\text { Monte Mor } \\
\text { B - Varv. Itu } \\
\text { A - Congl aren. congl, } \\
\text { Trossos e finos, varv. }\end{array}$ & $\begin{array}{l}\text { Aren. Carva de } \\
\text { Monte Mor } \\
\text { Sed/pred. arenosos } \\
\text { Tilito Salto }\end{array}$ & $\begin{array}{l}\text { Ciclos de aren. } \\
\text { pros. e congl. } \\
\text { Biamict passando } \\
\text { acima a aren. } \\
\text { mto finos e silt. } \\
\text { aren. } \\
\text { Ritu. locais } \\
\text { Raros leitos delg, de } \\
\text { calc. aren. Restos } \\
\text { veg. e carvao } \\
\text { escassos Estrat. } X \\
\text { de porte maior na } \\
\text { base, diminuindo } \\
\text { para cima. }\end{array}$ & $\begin{array}{l}\text { Aren. C. granod. } \\
\text { ascend.; aren." } \\
\text { macicos ou c. estral. } \\
X \text {; ditmict. macico } \\
\text { ou acamado congl. c. } \\
\text { ou sem estrat. X: } \\
\text { lentes lamíticas. } \\
\text { Diamict. macipos } \\
\text { intercalados c.; } \\
\text { corpos desc. de aren. } \\
\text { e argil. }\end{array}$ & $\begin{array}{l}\text { Diamict., congl. e } \\
\text { aren. grossos, } \\
\text { macicos e estratifi- } \\
\text { cados, Tit., estrias } \\
\text { glaciais, pavimento } \\
\text { de clastos. Lamitos } \\
\text { folh. em menor } \\
\text { quantida- de. }\end{array}$ & $\begin{array}{l}\text { Aren., c. granod. } \\
\text { ascend. Aren. } \\
\text { grossos, macipos e } \\
\text { estratifichdos. } \\
\text { Til. e diamict. }\end{array}$ \\
\hline
\end{tabular}


ITroLook

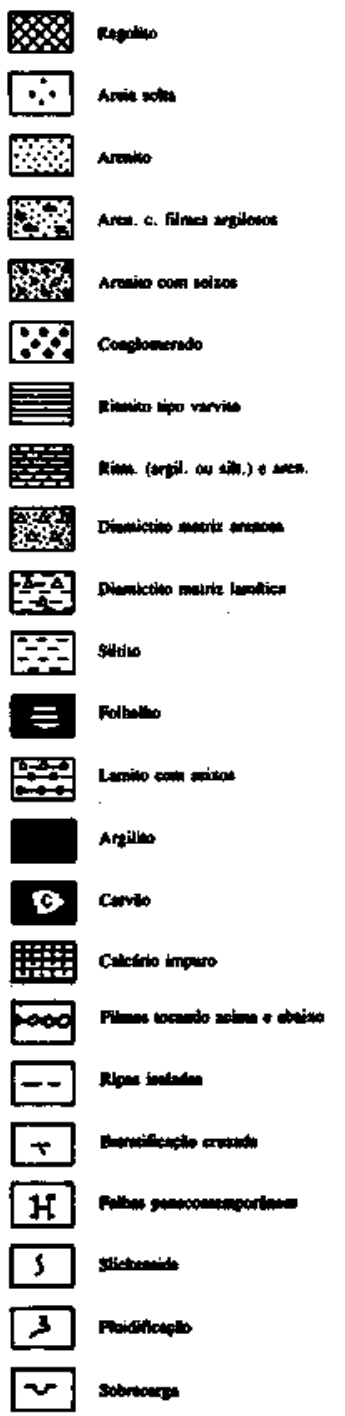

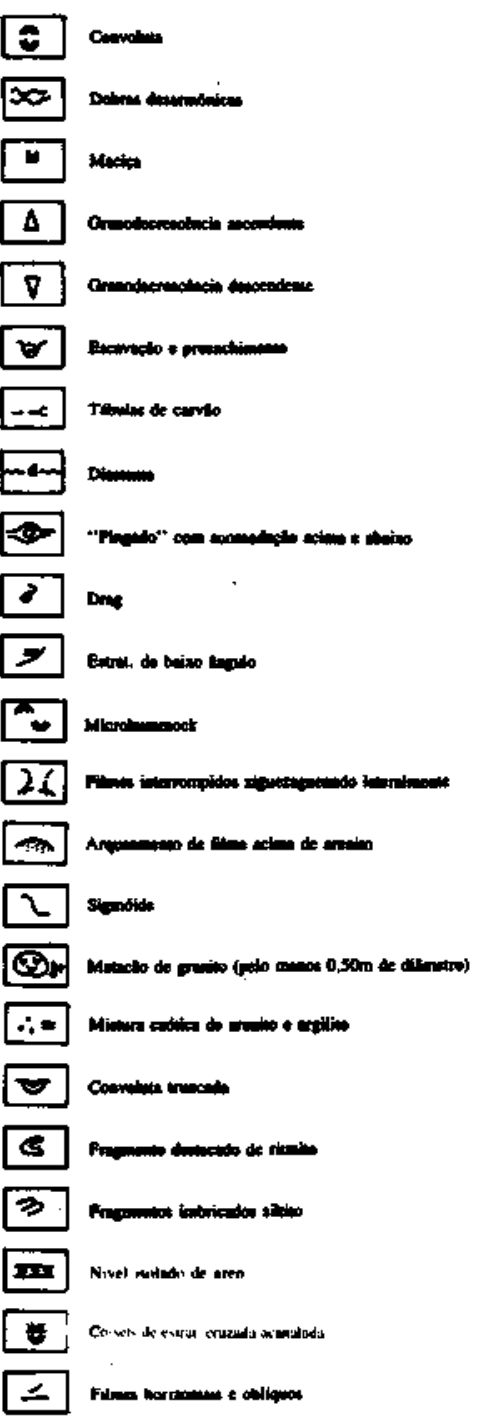

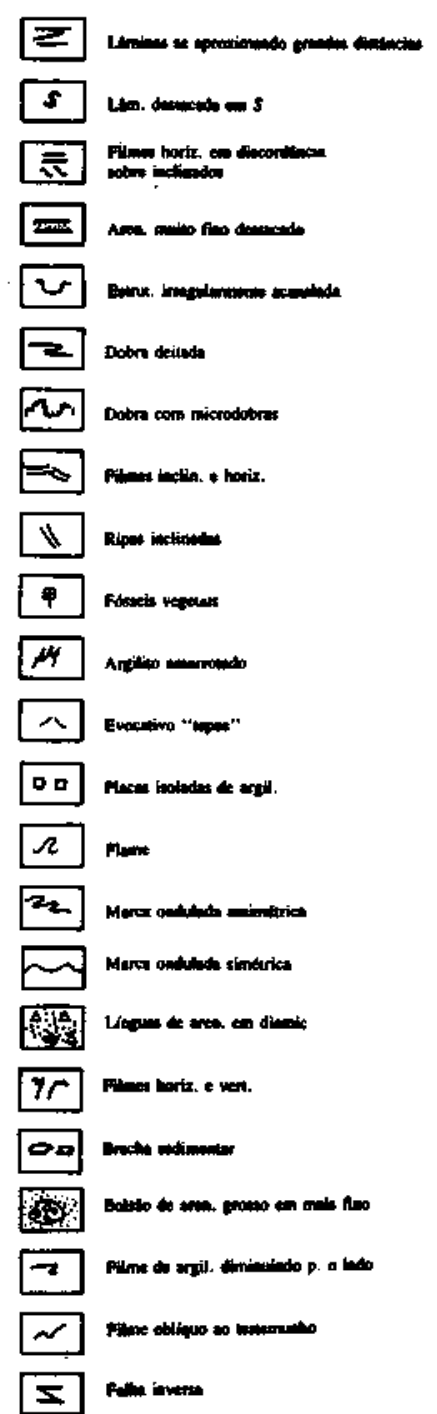

Figura 1 - Legenda das litologias perfuradas pelos poços do Instituto Geológico e estruturas exibidas pelos sedimentos perfurados

Figure 1 - Symbols used for lithological descriptions of the wells drilled by the "Instituto Geológico" and structures as seen at the cores of the wells drilled by the Instituto Geológico

através de um diamictito basal, passando a arenitos e siltitos com pequenas intercalações de diamictitos.

No poço da Geomater próximo à Araçoiaba da Serra (Massoli 1991), a Formação Itu se resume nos 18m basais, também com um diamictito no contato com o embasamento cristalino, constituído de granito róseo polido e estríado e aqui, também, a passagem do diamictito para arenitos e destes para ritmito siltito-argilito, ocorre por meio de granodecrescência.

Em todas estas ocorrências da Formação Itu, como visto, o contato do diamictito basal com o embasamento cristalino se apresenta como uma superfície polida e estriada. Em uma das sondagens da Schincariol, inclusive o diamictito basal está polido e estríado (Mezzalira 1969). Além desta característica, associada ao diamictito basal, este exibe matacões, geralmente de granito, alguns com diâmetros de 1 metro ou mais (Mezzalira 1969,1980, Massoli 1991). Na região entre Sumaré e Monte Mor, Mezzalira (1972) noticiou a presença de um grande bloco errático, partido em duas partes, com dimensão total de $6 \mathrm{~m} \times 5,30 \mathrm{~m} \times 3,70 \mathrm{~m}$.

A Formação Itu se constitui em uma formação marginal em relação à bacia de sedimentação. São elásticos transgressivos, essencialmente arenosos. Sua idade seria pré-G na área de Araçoiaba, visto que os fósseis marinhos que ocorrem acima desta formação seriam $\mathrm{G}$ ou mesmo pré-G, contudo, ainda neocarboníferos, Stephaniano ou mais antigo, segundo Lima et al (1983). Na região de Itu, sua idade seria mais moderna, visto situar-se logo abaixo dos "varvitos clássicos de Itu" de idade II, ou seja eopermiana, segundo Dino et al (1987).

Teria ocorrido transgressão, no tempo, da Formação Itu, segundo a direção $\mathrm{S}$ W-NE, com os sedimentos mais novos a NE.

FORMAÇÃO CAPIVARI A presença do mar durante os tempos Itararé no Estado de São Paulo, é atestada por fósseis marinhos, registrados em quatro ocorrências: a. Araçoiaba; b. Capivari; c. Hortolândia; d. Itaporanga. Destas quatro localidades, a única que evidencia salinidade normal para mar, ou seja, sem influência sensível de água doce, é a de Capivari, que exibe maior variabilidade de braquiópodes, os quais são articulados, além de moluscos e crinóides.

Os fósseis de Araçoiaba, Hortolândia e Itaporanga são menos diversificados, de pequeno tamanho, com predomínio de braquiópodes inarticulados, sugerindo águas de salinidade abaixo da normal. Estas três últimas ocorrências, portanto, situar-se-iam em áreas mais marginais em relação à de Capivari. 


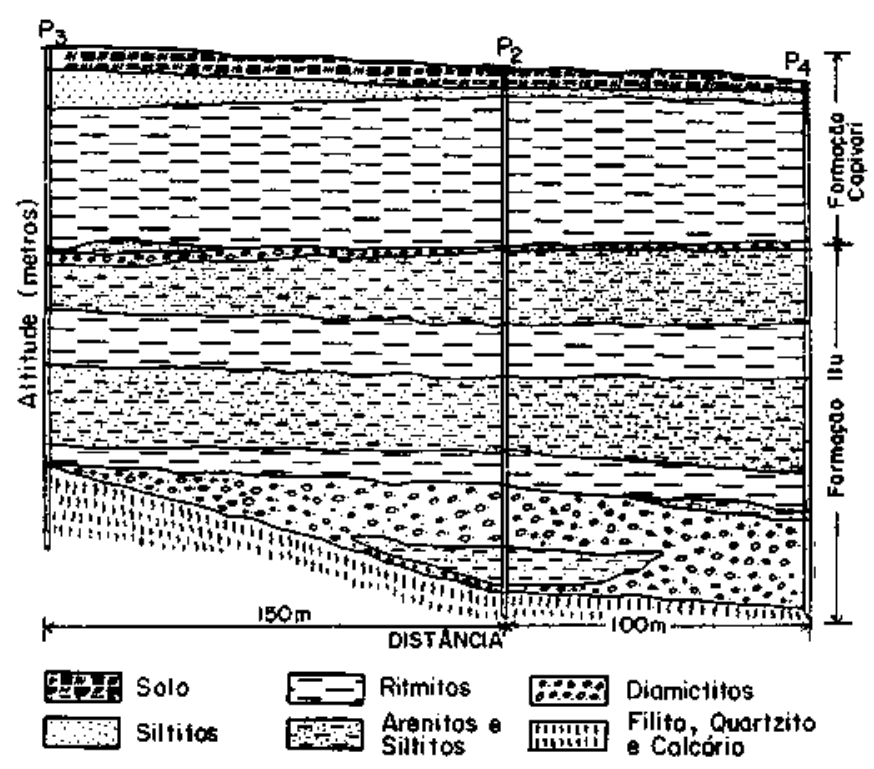

Figura 2 - Seções dos poços perfurados em Schincariol, município de Itu (Segundo Mezzalira, 1969), com nossa interpretação para as Formações Itu e Capivari Figure 2 - Geological section through three wells drilled at Schincariol, Itu municipality, State of S. Paulo (after Mezzalira, 1969) with the formations as here interpreted

Os fósseis das quatro ocorrências referidas acima, são de idades diferentes. Os de Araçoiaba seriam pré-G, do Neocarbonífero, Stephaniano, segundo Lima et al. (1983). Os de Capivari-Hortolândia, H2, ou seja do Eopermiano, base do Artinskiano, segundo Saad (1977). Rocha-Campos (1966) e Rocha-Campos \& Rosier (1978) atribuem os fósseis marinhos de Capivari-Hortolândia ao Eopermiano, com base, principalmente, no gastropode Peruvispira delicata, além do braquiópode Attenuatella. Saad (1977) colocou os fósseis marinhos de Itaporanga junto à sua "microflora ÜI", cuja idade estaria entre $\mathrm{H} 2$ e 14, portanto mais nova que a de Capivari. Embora precária, esta datação é a única disponível.

Todos os fósseis destas quatro ocorrências, atestariam, contudo, uma única transgressão, a qual caracterizaria a Formação Capivari.

Os fósseis marinhos estão contidos em siltito mal selecionado e lamito síltico. Em condições mais marginais ocorrem depósitos exibindo pistas e rastros de organismos além de palinomorfos mas sem os braquiópodes, moluscos e crinóides. Incluem-se entre estes depósitos, ritmitos formados por lâminas delgadas de argilitos, mais escuras, e siltitos, mais claras e, por vezes com intercalações centimétricas silto-arenosas com marcas onduladas, ritmitos estes que incluem os chamados "varvitos clássicos de Itu". Estes depósitos seriam reflexo de corpos de água de baixa energia, marinhos ou costeiros, sobrepostos aos arenitos da Formação Itu devido a transgressão marinha. É possível que tais depósitos tenham se formado em diferentes subambientes dentro do Itararé, porém atestam fase de afogamento e são, por isso, incluídos na Formação Capivari.

É proposto, neste trabalho, como holoestratótipo da Formação Capivari, a seção do poço C-IG/90 perfurado na área sul do perímetro urbano de Capivari. Neste poço, basicamente, ocorrem três pacotes litológicos:

a. O pacote superior, de 11 a $61 \mathrm{~m}$ de profundidade (acima de $11 \mathrm{~m}$ ocorre regolito). Este intervalo, com $50 \mathrm{~m}$ de espessura, caracteriza-se por ritmito fino, tipo "varvito de Itu", com raros níveis de argilito ou siltito. É um pacote homogêneo, quase sem estruturas, a não ser por suaves ondulações e pequenas depressões das lâminas sílticas sobre as argilosas, interpretadas como causadas por sobrecargas. Somente de $38 \mathrm{~m}$ para baixo ocorrem perturbações causadas não só por clastos "caídos" com acomodações das lâminas acima e abaixo dos clastos, como também por pequenas convolutas, porções de lâminas destacadas em forma de S, falhas penecontemporâneas, camadas truncadas de ritmito e fragmentos tabulares de ritmitos com acomodações de sedimentos acima e abaixo, possivelmente resultado de canibalismo e pequeno transporte.

b. Abaixo deste primeiro pacote, ocorre um pacote transicional entre o primeiro e o terceiro pacotes, este último colocado na base do poço. São freqüentes, neste segundo pacote, ritmitos constituídos por alternância de camadas centimétricas de siltito e argilito, intercaladas por lamito maciço com granules e pequenos seixos, e por siltitos. A partir do contato com o pacote inferior (3), ocorre granodecrescência ascendente, passando para arenito muito fino, siltito e ritmito, ocorrendo apenas um corpo de diamictito de $7 \mathrm{~cm}$ de espessura, lamítico, estratificado.

Neste pacote são freqüentes deformações de sedimentos, com contatos irregulares, verticais, de diferentes litologias, convolutas, dobras desarmônicas de leitos argilosos, imbricamento de fragmentos de siltito, lâminas irregularmente anastomosadas e porções de ritmitos destacados e ressedimentados. c. A litologia predominante do terceiro pacote, situado na base do poço, é de arenito, de granulação média na base, passando a muito fina no topo. Arenitos de granulação grossa são muito raros. Granules e seixos milimétricos são esporádicos. Leitos argilosos, raros na base, tomam-se mais freqüentes no topo, ocorrendo de forma irregular e em certos níveis, muitas vezes imprimindo à rocha, características de ritmito arenito-argilito.

Foram reconhecidos dois níveis delgados de diamictito, o mais importante no topo deste pacote. Ambos os níveis exibem leitos argilosos esporádicos, imprimindo às rochas, certa estratificação. O nível inferior, 84 a $83 \mathrm{~m}$ de profundidade, exibe pequenos seixos esparsos nos leitos argilosos, distribuídos em uma convoluta, a 83,6 $\mathrm{m}$ de profundidade. $\mathrm{O}$ topo deste diamictito é lamítico, com fatias delgadas, descontínuas, de siltito carbonoso, dispostas horizontal e inclinadamente.

Neste intervalo, foram verificadas granodecrescências ascendentes e dois diastemas. Ocorrem, também, passagens irregulares de litologias na vertical, bolsões de arenito de granulação média, circundados por arenito muito fino, fragmentos de arenitos e ritmitos envolvidos por arenitos de outras granulações, às vezes, com acomodações dos sedimentos acima e abaixo destes fragmentos, pequenas falhas com ou sem drags, dobras desarmônicas e convolutas. A $87 \mathrm{~m}$ foi verificado um pequeno dique elástico de arenito.

As características deste intervalo sugerem um lobo submarino, onde predominariam processos gravitacionais, avançando sobre um corpo de água de baixa energia. Fluxos gravitacionais sucessivos seriam responsáveis por diastemas e canibalismos de camadas pretéritas.

Este pacote basal foi denominado de intervalo I (Fig. 3), por representar o início da sedimentação do poço.

$\mathrm{O}$ pacote intermediário, intervalo $\mathrm{O}$, pode refletir uma flutuação transgressiva do mar, ou mesmo variação lateral na deposição do lobo submarino descrito no intervalo anterior.

O pacote superior, intervalo II, é homogêneo, quase sem estruturas, a não ser suaves ondulações e pequenas depressões das lâminas sílticas, interpretadas como causadas por sobrecargas. Somente abaixo de $38 \mathrm{~m}$ ocorrem perturbações causadas por seixos "caídos", pequenas convolutas, porções de lâminas destacadas em S, pequenas falhas, camadas truncadas de ritmitos e fragmentos de ritmitos, ao que parece originados por canibalismos e redeposições.

O intervalo III representaria as condições de "costa afora" (offshore) (Suguio 1992), com alguma influência do lobo submarino somente abaixo de $38 \mathrm{~m}$. Acima desta profundidade foi completa a influência de costa afora com deposição, possivelmente por correntes de turbidez de baixa densidade. 


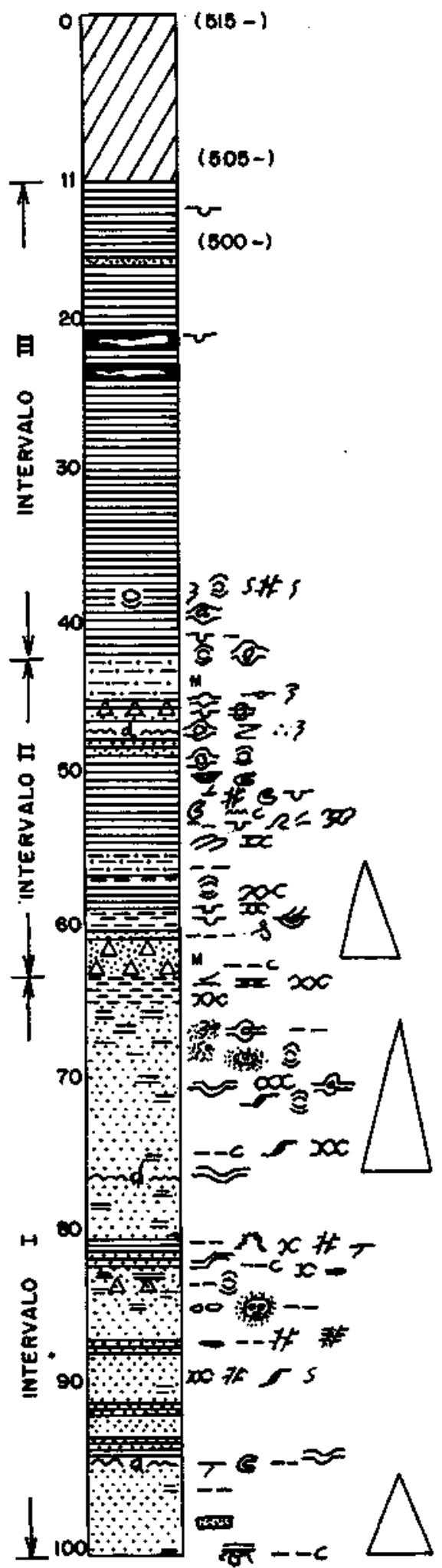

Figura 3 - Poço C-IG/90: Seção proposta para holoestratótipo da Formação Capivari

Figure 3 - C-IG/90 well, here selected for the stratotype of the Capivari Formation

Apenas para ressaltar diferenças de litologias de poços muito próximos geograficamente, chama-se a atenção aqui, para o poço C2-IG/89, que atravessou $250 \mathrm{~m}$ contínuos de elásticos grossos, predominantemente arenitos quartzosos e arcosianos e subsidiariamente lâmitos com granules e seixos e,
Tabela 2 - Poço C-IG/90 - Estruturas sedimentares e interpretações genéticas

Table 2 - C-IG/90 well - Sedimentary structures and genetic interpretations

\begin{tabular}{|c|c|c|c|c|}
\hline $\begin{array}{l}\text { Lam. } \\
\text { cruzzadz }\end{array}$ & & $59-59,5$ & $87 ; 94,7$ & \multirow[t]{7}{*}{$\begin{array}{l}\text { Correntes } \\
\text { Laminares }\end{array}$} \\
\hline $\begin{array}{l}\text { Granod. } \\
\text { ascend. }\end{array}$ & & $59,5-61,5$ & $\begin{array}{l}62,5 ; 66-76 ; \\
96-101,4\end{array}$ & \\
\hline $\begin{array}{l}\text { Acomodaçầo. } \\
\text { seixos }\end{array}$ & 39 & 45,4 & $\begin{array}{l}67,7 ; 70 \\
80,3\end{array}$ & \\
\hline $\begin{array}{l}\text { Ondul. } \\
\text { anastomasada. }\end{array}$ & & $53-55,5$ & $\begin{array}{l}70-78 ; 80,9 ; \\
82 ; \\
89,5-100,3\end{array}$ & \\
\hline $\begin{array}{l}\text { Ondul. } \\
\text { desarmónica. }\end{array}$ & & 58 & $\begin{array}{l}64-65 ; 80 \\
3-80,5\end{array}$ & \\
\hline Silt. imbricado. & & $53-55,5$ & & \\
\hline $\begin{array}{l}\text { Lam. } \\
\text { aproximando. } \\
\text { gde.distincia. }\end{array}$ & $34-36$ & & & \\
\hline $\begin{array}{l}\text { Contados.irreg. } \\
\text { litol. }\end{array}$ & & & 67.7 & \multirow[t]{9}{*}{ Deslizes } \\
\hline Bolsötes & & & 68,$5 ; 85,4$ & \\
\hline Brechas sed. & & 45,4 & $83,5-85,4$ & \\
\hline Ripas isolad. & 41 & $\begin{array}{l}47-48 \\
53,61\end{array}$ & $\begin{array}{l}68,5 ; \\
80,4-87 \\
94,8 ; 101,4\end{array}$ & \\
\hline Ripas torcidas. & 38 & $47-52$ & 94,7 & \\
\hline Ripis inclinadas. & $39 ; 42$ & $51-53$ & $\begin{array}{l}64 ; 70,3-78 ; \\
80,4-82\end{array}$ & \\
\hline $\begin{array}{l}\text { Folss slick(s) } \\
\text { drag (d) }\end{array}$ & $38(s)$ & 51 & $\begin{array}{l}70,3(\mathrm{~s}) ; \\
75,3 ; \\
80,3-82, \\
87-87,5(\mathrm{~s}, \mathrm{~d}) \\
\end{array}$ & \\
\hline $\begin{array}{l}\text { Dobras } \\
\text { compostas (c) } \\
\text { amplas e } \\
\text { baixas (a) } \\
\text { deiladas (d) }\end{array}$ & & $\begin{array}{l}44,8 ; 47 \text { (a) } \\
47,5 \text { (d) }\end{array}$ & $\begin{array}{l}80,3 \text { (c) 70; } \\
74-74,8 ; 91 \\
2(a)\end{array}$ & \\
\hline Conwolutas & $38 ; 42$ & 48,$8 ; 58$ & $\begin{array}{l}68,5 ; 70,3 \\
74,8 ; 83,6\end{array}$ & \\
\hline $\begin{array}{l}\text { Sobrecarga flame } \\
\text { (f) }\end{array}$ & $\begin{array}{l}13,5 ; 21 ; \\
24\end{array}$ & $\begin{array}{l}44,8-51 ; \\
59-59,550 \\
53(\mathrm{O}\end{array}$ & & \multirow[t]{4}{*}{$\begin{array}{l}\text { Sedimenta- } \\
\text { çlo rápida }\end{array}$} \\
\hline Difipiro & & $\begin{array}{l}45,1 ; 47,5 ; \\
50\end{array}$ & 68,4 & \\
\hline Dique clast. & & & 87 & \\
\hline Fluidificaçso & 38 & 47 & $\begin{array}{l}64 ; 80,3 ; \\
85,5-87 ; \\
94,7 \\
\end{array}$ & \\
\hline Diastema & & $47 ; 50 ; 59$ & $\begin{array}{l}64 ; 76 ; 94,8 ; \\
100,3\end{array}$ & Erosto \\
\hline Carväo; veg. & & & $\begin{array}{l}62,5 ; 75,3 ; \\
80,3 ; 101,4\end{array}$ & $\begin{array}{l}\text { Dep. } \\
\text { orghinica }\end{array}$ \\
\hline Maciça & & $43 ; 61$ & $61,5-62$ & \multirow{2}{*}{$\begin{array}{l}\text { Origens } \\
\text { diversas }\end{array}$} \\
\hline Intervalo & $\operatorname{lII}_{11 * 42}$ & $\begin{array}{l}\text { II } \\
42-61,5\end{array}$ & $\begin{array}{l}\text { I } \\
61,5-101,4\end{array}$ & \\
\hline
\end{tabular}

localmente, diamictitos. Estes elásticos grossos assentam sobre ritmitos tipo "varvito de Itu". O perfil litológico deste poço foi publicado em Petri (1992, Fig. 9).

A figura 8 apresenta, de forma sintética, nossa interpretação das relações das Formações Itu e Capivari.

Sugere-se, aqui, que a Formação Tietê, tal como redefinida por Fúlfaro et al (1984), poderia ser sinônima da Formação 
Itu. Se o mergulho regional não for o admitido na literatura, para a área em questão, tanto no que diz respeito ao seu valor em grau como ao seu rumo, ou se ocorreram falhamentos com elevação de blocos na área Tietê-Jumirim, o resultado seria a passagem lateral dos arenitos aqui colocados na Formação Itu e os interpretados por Fúlfaro et al (1984) como da Formação Tietê.

Os arenitos da região Tletê-Jumirim-Cerquilho, considerados aqui como pertencentes a Formação Capivari, passam, gradativamente, para os sedimentos finos da Formação Tatuí, como, aliás, Fúlfaro et al (1984) já tinham observado.

Os $24 \mathrm{~m}$ superiores do poço de Jumirim (J-IG/86, Fig. 4) são caracterizados por arenitos muito finos, laminados, intercalados por siltítos, calcários e arenitos de granulação média, bem estratificados, de cores alternadamente chocolate, amarela, creme e cinza. São acamados em condições de baixa energia, tendo sido considerados como pertencentes a Formação Tatuí.
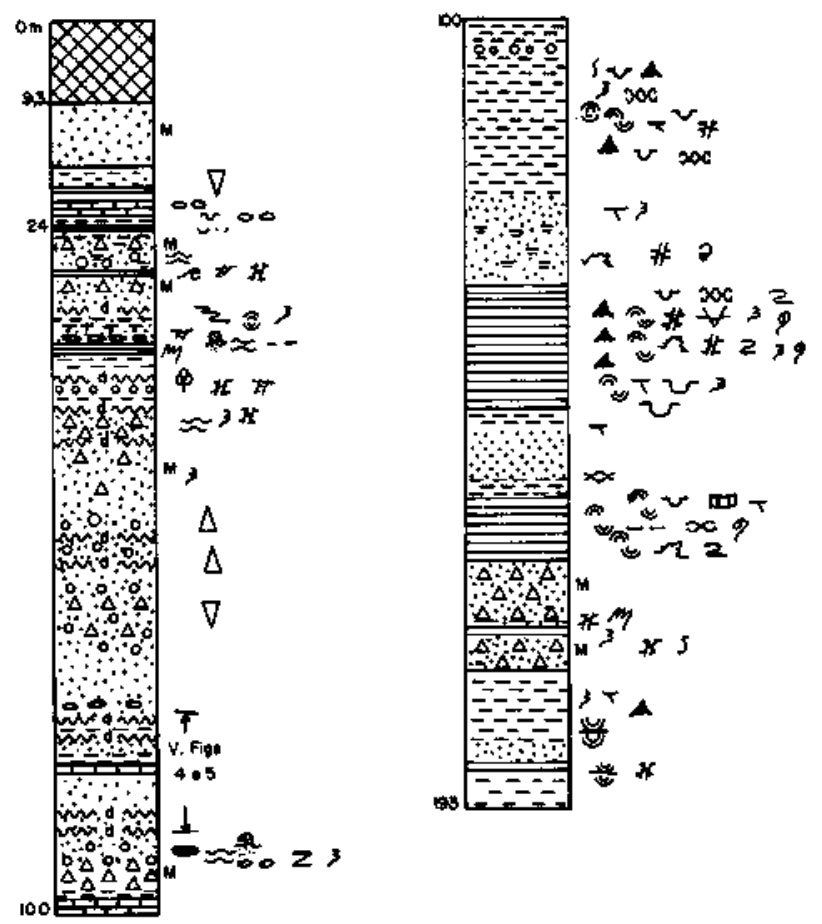

\section{LEGENDA}

\begin{tabular}{|c|c|c|c|}
\hline 00 & PELOTAS OE ARGILA & A & RPA TORCTDA DE AREN. \\
\hline$\checkmark \checkmark$ & $\begin{array}{l}\text { LAMIMAS AFGILOSAS } \\
\text { INTERROMPFOAS }\end{array}$ & $60 \%$ & AREN. CONGLOMERATICO \\
\hline$T T$ & SILT. CALCIFEAO & II & 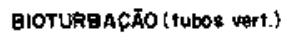 \\
\hline 00 & CAM. FORMADA POR GRAN & $\infty$ & OONCFECAO CALC EM SILT \\
\hline
\end{tabular}

Figura 4 - Poço Jumirim, J-IG/86 (Para a localização deste poço, vide Petri 1992, Fig. 1, p. 8). Os sedimentos perfurados acima de 24 m são considerados da Formação Tatui e abaixo, Itararé

Figure 4 - Lithological section of the J-IG/86 well. Note the lithological and structural diferences between 9-24m deep Tatuí Formation and 24-193 m deep Capivari Formation

De 24 a $100 \mathrm{~m}$ de profundidade, predominam arenitos com ou sem cimento calcífero, sendo subsidiários diamictitos arenosos. De 100 a 193 m, base do poço, ocorre uma sucessão de

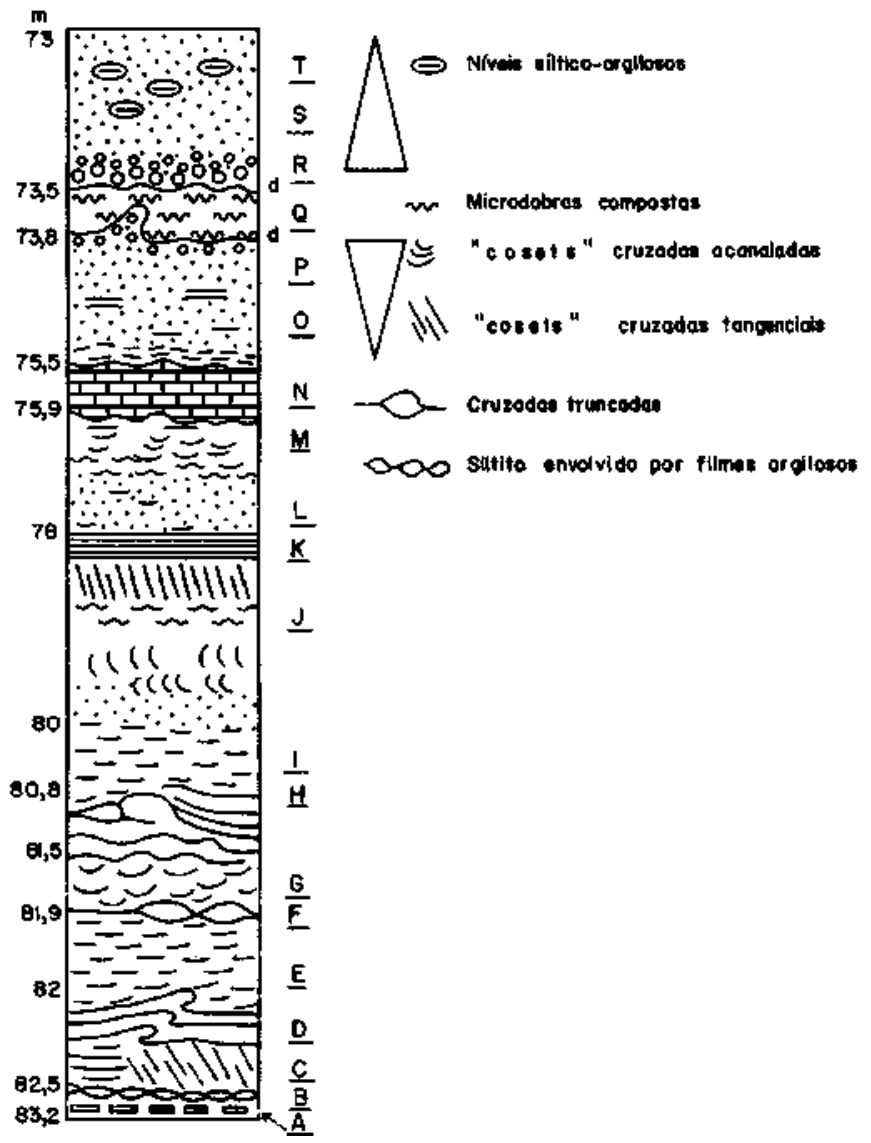

Figura 5-Poço J-1G/86: coluna litológica do intervalo 83,2 m a $73 \mathrm{~m}$. Significado das letras: T. arenito fino com níveis argilosos. $\boldsymbol{S}$. arenito médio. $\boldsymbol{R}$. arenito conglomerático. $\boldsymbol{Q}$. siltito com microdobras compostas. Fragmentos isolados de siltito tabular. Na base, faixas argilosas formando ângulo de $30^{\circ} \mathrm{em}$ relação ao siltito de cima, em contato, abaixo, com diastema, com projeção do arenito médio de baixo. $\boldsymbol{P}$. arenito médio. $\boldsymbol{O}$. arenito muito fino passando, abaixo, para siltito com concentrações de películas argilosas. $\mathbf{N}$. calcário impuro, com muitos clastos. M. siltito com películas argilosas preenchendo cosets cruzados acanalados. L. arenito muito fino, com muitas películas argilosas. $\boldsymbol{K}$. argilito chocolate. J. arenito muito fino, com películas argilosas e "cosets" cruzados tangenciais. Cores variadas tendendo para roxo. I. siltito passando, irregularmente, para arenito muito fino. $\boldsymbol{H}$. ritmito deformado por falhas e cruzadas truncadas. G. siltito com cosets cruzados acanalados. $\boldsymbol{F}$. siltito com cruzadas truncadas. E. siltito micáceo. D. ritmito com dobras assimétricas, interpretadas como causadas por deslizes. C. ritmito com cosets cruzados tangenciais. B. siltito envolvido por películas argilosas. A. ritmito com leitos argilosos interrompidos. Well $J-I G / 86$ Lithologies of the 83,2-73 m

Figure 5 - The following letters mean: T. fine sandstone with argillaceous films. S - medium sandstone. R. conglomeratic sandstone. Q. Siltstone with complex microfolds. Isolated fragments of thin uniform siltstone. Argillaceous films dipping about $30^{\circ}$ from the complex microfolds siltstone above, meeting a diastem surface below. P. medium sandstone. O. coarsening upward from siltstone with argillaceous films to very fine sandstone. $\mathbf{N}$. calcareous sandstone. M. cosets of small trough crossbeds draped with siltstones with argillaceous films. L. very fine sandstone with argillaceous films. K. chocolate mudstone. J. very fine sandstone with argillaceous films and cosets of tangential trough crossbeds. Variegated colors mostly purple. I. coarsening upward from siltstone to very fine sandstone. H. truncated crossbed rythmites with normal faults.G. trough crossbed sets of siltstone or very fine sandstone. F. truncated crossbed sets of siltstone or very fine sadstone. E. micaceous siltstone. D. assymmetrical folds in rythmite believed to be developed through slumps. C. rythmite with tangential crossbed sets. B. siltstone with argillaceous films. A. rythmite with isolated pieces of argillaceous beds 
siltitos, rítmitos, arenitos muito finos, arenitos conglomerations e diamictitos arenosos.

As características comuns de todos estes arenitos pré-Tatuí, estão relacionados abaixo:

a. Espessuras contínuas apreciáveis, da ordem de dezenas de metros, chegando, mesmo, em alguns casos, a mais de $200 \mathrm{~m}$, apenas com intercalações subsidiárias de diamictitos arenosos. b. Podem ocorrer delgadas camadas de carvão e fragmentos de plantas carbonizadas, exibindo sinais de transporte. Em testemunhos do poço J-IG/86 ocorrem caules carbonizados, alguns com comprimento que ultrapassam $20 \mathrm{~cm}$, desconhecendo-se o comprimento total por estarem cortados pela sonda. Plantas carbonizadas também aparecem em elásticos finos ou sob a forma de clastos em arenito ou diamictito. Manchas carbonosas equidimensionais também são encontradas.

c. Ciclos granodecrescentes ascendentes e, mais raramente, descendentes, freqüentemente com contato basal erosivo.

d. No poço J-IG/86 aparecem, em certos níveis, sedimentos com cores roxas e chocolates, em alguns casos associados com lâminas descontínuas de argilito.

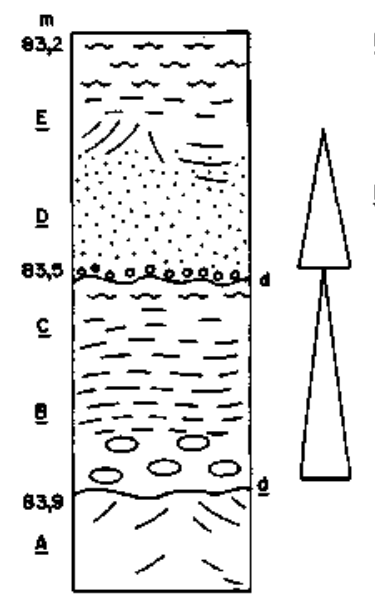

E Laminas interrampidat

D Arwallo: conglomeretico, possondo of fho mo

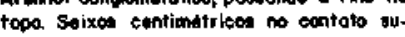
perior do didatemo.

G Lomino: interromatidor

A Siltito oom lominat ardlotcs. Polrognos do loma alongados poraleiamente o tuperficie dit diestema.

A Ritmitos fortuminte onduladol, sem selicos "cordon" al ate $14 \mathrm{em}$ de dionmitro.

$\wedge$

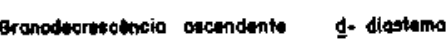

Figura 6 - Poço J-IG/86 - coluna litológica do intervalo $84-83,2 \mathrm{~m}$. well J-IG/86

Figure 6-I- IG/86 well lithologies of the 84-83,2 $m$ interval

$\mathrm{Na}$ região de Jumirim, isto é, nas camadas do topo de Itararé, verificam-se evidências de sedimentação subaquosa. Estes depósitos, constituídos, predominantemente, de arenitos e diamictitos são interpretados como turbiditos, depositados em um lobo submarino. Transicionam, para o topo, para ritmitos, inclusive com intercalações de camadas calcárias, da Formação Tatuí, representando o máximo da transgressão marinha.

\section{A SITUAÇÃO ESPECÍFICA DE CAPIVARI-RAFARD}

Os oito poços perfurados na região Capivari-Rafard, aqui estudados, estão localizados ao sul, sul-sudeste, sul-sudoeste e nordeste da cidade de Capivari, envolvendo distâncias de 500 $\mathrm{m}$ a $2.500 \mathrm{~m}$ entre os poços do lado sul e $2.000 \mathrm{~m}$ entre os do lado norte. Infelizmente não foram perfurados poços com testemunhagem completa no lado noroeste da conurbação.

Abaixo estão relacionados os poços perfurados, com as profundidades atingidas e as cotas das bocas dos poços.

$\mathrm{R}=$ Rafard; $\mathrm{C}=$ Capivari; $\mathrm{IG}=$ Instituto Geológico da Secretaria de Estado do Meio Ambiente. Os números de 85 a 90 se referem aos anos de início das perfurações. Os que não obedecem este sistema de identificação foram perfurados antes de 1985.
Tabela 3 - Poço J-IG/86 - Estruturas sedimentares e interpretações genéticas

Table 3 - Well J-IG/86 - Sedimentary structures and genetic interpretations

\begin{tabular}{|c|c|c|c|c|}
\hline Gretas & & $\begin{array}{l}24 ; \\
78,7-83,8\end{array}$ & & Exposicto \\
\hline $\begin{array}{l}\text { Granodec. } \\
\text { descendente }\end{array}$ & $16-21$ & $66-75,5$ & & Progradach \\
\hline $\begin{array}{l}\text { Boa separacto } \\
\text { granul. }\end{array}$ & $13-23,5$ & $\begin{array}{l}27-45,5 \\
86,7-89,8\end{array}$ & $\begin{array}{l}130,5-145,1 \\
182,7-193\end{array}$ & $\begin{array}{l}\text { Corrente } \\
\text { laminar }\end{array}$ \\
\hline $\begin{array}{l}\text { Laminacto } \\
\text { cruzada }\end{array}$ & & $75,5-83,1$ & $\begin{array}{l}110,5 ; \\
122,5 ; \\
142-155,7 \\
186,5-193\end{array}$ & \\
\hline $\begin{array}{l}\text { Marcas } \\
\text { onduladas }\end{array}$ & $23-23,5$ & 33: 78-78,8 & & \\
\hline $\begin{array}{l}\text { Granodec. } \\
\text { ascendente }\end{array}$ & & $\begin{array}{l}32-33,5 \\
51-50 \\
73-73,5 \\
83,5-83,9\end{array}$ & & \\
\hline $\begin{array}{l}\text { Trunceadas por } \\
\text { ondas }\end{array}$ & & $75,5-81,5$ & $\begin{array}{l}110,5 \\
131-142 \\
155,7-159,5\end{array}$ & \\
\hline $\begin{array}{l}\text { Ondol. } \\
\text { desarmonia }\end{array}$ & & $\begin{array}{l}35-36 ; 45-5 \\
78,7\end{array}$ & $\begin{array}{l}100-101,5 \\
130,5-157,1 \\
162,5-168,2\end{array}$ & \\
\hline Pelotas argila & $21-23,5$ & 89,8 & & \\
\hline $\begin{array}{l}\text { Ripas } \\
\text { isoladas }\end{array}$ & & $\begin{array}{l}35-36 ; \\
73-73,5\end{array}$ & 129,$5 ; 157,1$ & Deslizes \\
\hline $\begin{array}{l}\text { Fragimentos. } \\
\text { aren, torc. }\end{array}$ & & $35-36 ; 86,7$ & & \\
\hline $\begin{array}{l}\text { Falhas } \\
\text { inversa (i) }\end{array}$ & & $\begin{array}{l}29 ; 36-41,2 ; \\
73,89,889,5 \\
\text { (i) }\end{array}$ & $\begin{array}{l}106-110,5 ; \\
106,5 \text { (d); } \\
127,5 \\
\text { (d)-129.5; } \\
131 ; 142 ; \\
176-176,5\end{array}$ & \\
\hline $\begin{array}{l}\text { Dobras } \\
\text { composta (c) } \\
\text { deitada (d) } \\
\text { amarrotadas (a) } \\
\text { ampla (am) }\end{array}$ & & $\begin{array}{l}73-73,8(c) ; \\
79,6-82,1 \\
\text { (d): 39 (a); } \\
78(c) ; 83,9 \\
\text { (a); } 89,5 \\
\text { (am) }\end{array}$ & $\begin{array}{l}129,5(\mathrm{c} ; \\
\mathrm{am}) ; \\
131-142 \\
(\mathrm{am} ; \mathrm{d}) ; \\
133,5(\mathrm{c}) ; \\
168 \text { (d); } 173 \\
\text { (a) }\end{array}$ & \\
\hline Convoluta & & 33,$5 ; 79,6$ & $\begin{array}{l}101,5-110,2- \\
160\end{array}$ & \\
\hline $\begin{array}{l}\text { Sobrecarga } \\
\text { flame (f) }\end{array}$ & & $\begin{array}{l}29(f): 42,5 \\
78,7-83,2 \\
89,5(f)\end{array}$ & $\begin{array}{l}106,2-110,5 ; \\
117,3 \\
130,5-145,7\end{array}$ & $\begin{array}{l}\text { Sedimeth- } \\
\text { ço rapida }\end{array}$ \\
\hline Diśpiro & & & $\begin{array}{l}106,5 \\
117,3 \\
132,5-139 \\
186,5\end{array}$ & \\
\hline Fhuidificacto & & $\begin{array}{l}29 ; 33,5 \\
42,5 ; 52,5 \\
89,5 ; 99\end{array}$ & $\begin{array}{l}107,2 ; \\
122,5-142 ; \\
171,8-182,7\end{array}$ & \\
\hline Diastema & & $\begin{array}{l}33 ; 39 ; 41,2 ; \\
42 ; 46,3 \\
73,6 ; 73,8 ; \\
83,5 ; 83,9\end{array}$ & & Erosäo \\
\hline $\begin{array}{l}\text { Escovachao e } \\
\text { preenchimento }\end{array}$ & 23-23.5 & & & \\
\hline Bioturbacfo & & $78,83,2$ & 155.7 & Orgatica \\
\hline Pistas & & & \begin{tabular}{|l}
$135-136$ \\
157,2
\end{tabular} & \\
\hline Plantas fosseis & & $39-42$ & & \\
\hline Maciça & & $\begin{array}{l}26 ; 30,5 ; \\
47-49,3 ; \\
63-66 ; 92-99\end{array}$ & $\begin{array}{l}162,5-168,2 \\
172,1+172,7\end{array}$ & Origem div. \\
\hline Intervalos & 9,3-24 & $24-100$ & $100-193$ & \\
\hline
\end{tabular}

O alinhamento dos poços C2-IG/89, C-IG/87, C-IG/90, TA e R-IG/85 correponderia à direção (strike) admitida regional- 


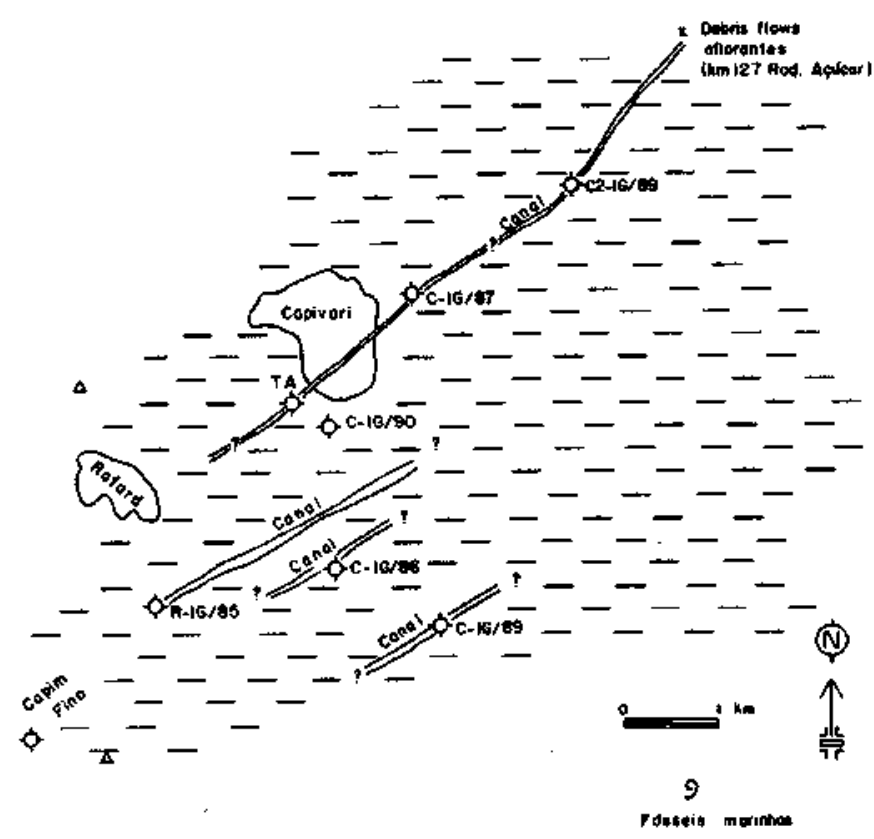

Figura 7-Paleogeografia proposta para a região CapivariRafard, durante o tempo representado pelos poços perfurados pelo Instituto Geológico

Figure 7 - Capivari-Rafard region: proposed paleogeopraphy during the time of deposition of the sediments cut by the studied wells

Tabela 4 - Relação dos poços perfurados na região CapivariRafard. A cota $500 \mathrm{~m}$ foi tomada como base para as comparações dos poços entre si

Table 4 - Wells drilled at the Capivari-Rafard region. The $500 \mathrm{~m}$ altitude was taken as basis for comparisons of the wells

\begin{tabular}{l|c|c}
\hline \multicolumn{1}{c|}{ Pofo } & Cota Boca (m) & Profundidade (m) \\
\hline 1 - R-IG/85 & 505 & 301,0 \\
2 - C-IG/86 & 510 & 301,0 \\
3 - C-IO/87 & 500 & 310,0 \\
4 - C-IG/89 & 540 & 275,5 \\
5 - C2-IG/89 & 500 & 268,0 \\
6 - C-IG/90 & 515 & 101,4 \\
7 - Capim Fino & 580 & 226,0 \\
8 - TA & 500 & 292,0 \\
\hline
\end{tabular}

mente. Torna-se assim possível estabelecer eventuais correlações temporais de camadas em cotas correspondentes. Naturalmente esta suposição pode conduzir a erros, devido a cinco fatores: a. Taxas diferentes de sedimentação de acordo com o processo deposicional; b. Compactação diferencial, maior para elásticos finos; c. Deslizes de camadas, com interrupção da sedimentação; d. Diastemas; e. Presença de falhas de grande rejeito. Quando possível, as correlações, localmente, poderiam ser feitas por níveis marinhos transgressivos. De acordo com o modelo aqui considerado, a sedimentação é produzida pelo antagonismo entre ambiente pouco energético e cunhas elásticas. Muitas vezes a inflexão de correntes de densidade pode superpor elásticos finos sobre grossos, o que não indicaria, necessariamente, níveis transgressivos.

Sob o ponto de vista de proporção de elásticos grossos para finos, em um extremo se situa o poço C2-IG/89, com espessura contínua de grossos $(250 \mathrm{~m})$ predominantemente constituídos de arenitos e, subordinadamente, lamitos com seixos esporádicos. Chama a atenção no pacote superior de elásticos grossos, a presença comum de fragmentos de carvão e restos de plantas carbonizadas transportadas e a presença comum de feldspatos caulinizados. A proporção de grossos para finos, neste poço, é de 250/13.Esteéopoço que exibe maicn: uniformidade litológica.

Os poços Capim Fino e C-IG/90, ao contrário, caracterizam-se por pequena proporção de elásticos grossos para finos, $34 / 55$ para o caso do poço C-IG/90. Contudo, este poço só atingiu $100 \mathrm{~m}$ de profundidade.

Os poços TA e C-IG/90, distantes entre si por apenas $500 \mathrm{~m}$, exibem, contudo, grandes contrastes de litologias, predominantemente grossos em TA e finos em C-IG/90.

O poço R-IG/85 exibe proporções de grossos para finos, da ordem de $57 \%$, o que o situa em posição intermediária. Este poço, em contraste com todos os descritos aqui, caracteriza-se por grande regularidade de sucessões de grossos e finos, ocorrendo, na passagem dos conjuntos grossos/finos, superficies erosivas.

Os poços R-IG/85 e C-IG/90 possuem um pacote contínuo de elásticos finos, com espessuras equivalentes, em tomo de $60 \mathrm{~m}$. Estes dois pacotes eventualmente poderiam ser correlacionáveis no tempo, embora situados a cotas diferentes mais altas em C-IG/90.

Os sedimentos finos dos poços Capim Fino e C-IG/90 foram interpretados como gerados em um ambiente onde imperariam condições de baixa energia. Também os sedimentos do poço $\mathrm{R}-\mathrm{IG} / 85$ teriam sido gerados em um ambiente de baixa energia. Contudo, aqui, as condições energéticas seriam periodicamente perturbadas por fluxos de detritos que atingiriam o mar através de canais submersos. Neste poço, estas flutuações foram agrupadas em três episódios caracterizados por diminuição gradativa de energia, refletida por granodecrescência ascendente. Novo aumento de energia causaria diastema e, em seguida, novo episódio. Talvez toda a seção do poço C-IG/90, que só chegou a 100,4 $\mathrm{m}$, possa ser correlacionada a parte superior, de águas mais calmas, do episódio intermediário do poço R-IG/85 (o poço R-IG/85 atingiu $301 \mathrm{~m}$ de profundidade).

Os sedimentos atravessados pelo poço C2-IG/89, depositados em condições de maior energia, foram interpretados como gerados por fluxos gravitacionais em um canal submarino, que atravessou o local onde hoje se situa a cidade de Capivari, e atingiu a região de costa afora ao sul desta cidade.

O poço C-IG/89 é o que está mais próximo, geograficamente, do afloramento com fósseis marinhos, distando deste cerca de $3 \mathrm{~km}$ no rumo sudeste. Este poço e os de sigla C-IG/86 e C-IG/87, possuem características intermediárias entre os poços Capim Fino, C-IG/90 e R-IG/85 de um lado e os poços TA e C2-IG/89 do outro. Os poços C-IG/86, C-IG/87 e C-IG/89 possuem cerca de $80 \%$ de elásticos grossos, mas distribuídos de forma uniforme. Eles foram interpretados como gerados em condições de fluxos gravitacionais.

São características comuns a todos os poços da região, a grande freqüência de estruturas interpretadas como geradas por correntes de densidade; menos freqüentemente, ocorrem estruturas interpretadas como geradas por correntes laminares, que aparecem em posição estratigráfica definida. É grande a freqüência de estruturas interpretadas como geradas por deslizes subaquáticos. Também são freqüentes intercalaçôes argilosas, geralmente sob a forma de pequenas lâminas dispostas irregularmente e, também, irregularmente espaçadas. Os diamictitos de matriz lamítica ou arenítica possuem espessuras reduzidas e foram interpretados como o resultado de fluxos gravitacionais; às vezes eles passam na vertical e na horizontal para arenitos ou lamitos. Esporadicamente, podem exibir intercalaçôes argilosas.

Pires \& Petri (1991) analisaram trinta afloramentos ao longo das rodovias que cortam a área e chegaram a conclusões concordantes com a interpretação de Stevaux et al. (1987) sintetizadas no bloco diagrama da figura 10 (p. 373). Neste bloco diagrama, a área de Capivari-Rafard está esquematizada como pertencente a um leque submarino. 
CONCLUSÕES 1.O Subgrupo Itararé na região estudada compreende sedimentos depositados durante um episódio transgressivo marinho, e portanto, correponde a uma seqüência retrogradacional.

2. A seqüência retrogradacional foi dividida em duas grandes unidades: A Formação Itu, predominantemente arenosa, corresponde à depósitos fluvio-deltaícos, e dessa forma são depósitos marginais e não necessariamente basais; e a Formação Capivari, constituída predominantemente por depósitos finos e subordinadamente arenitos e diamictitos. A Formação Capivari está representada por depósitos marinhos que transgridem sobre a Formação Itu. O contato entre as formações Itu e Capivari é transicional, tanto verticalmente como horizontalmente.

3. A Formação Tatuí corresponde ao máximo de transgressão marinha. $\mathrm{Na}$ área está representada por ritmitos (inclusive calcários) com grande continuidade lateral e se sobrepõem aos sedimentos da Formação Capivari através de contato transicional.

4. Os arenitos fluvio-deltaícos da área de Cerquilho-Tietê designados Formação Tietê por Fúlfaro et al. (1984) correspondem aos depósitos da Formação Itu (basal). Estes depósitos podem ser mapeados em continuidade lateral com os arenitos da Formação Itu (na região de Salto/Itu), através da calha do Rio Tietê.

Salvo repetições causadas por falhamentos regionais (o que não devem ser descartadas), a espessura do Subgrupo Itararé, na área de afloramento entre Tietê e Itu, não deve exceder muito o valor de $300 \mathrm{~m}$.

Esses sedimentos são representativos de um único episódio transgressivo (carbonífero-Permiano) que expandiu os limites pretéritos da bacia sedimentar, avançando sobre áreas até então "continentalizadas".

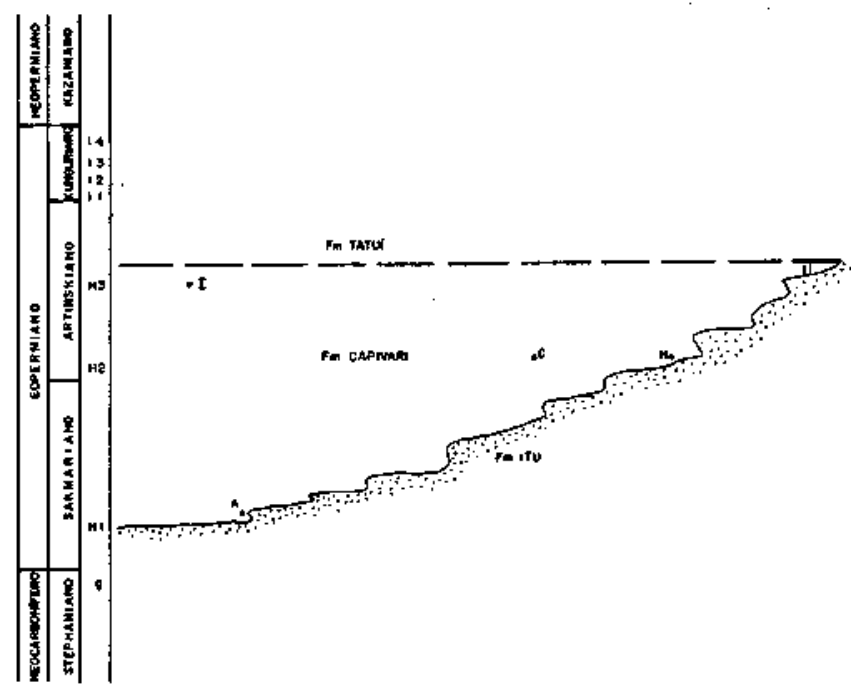

Figura 8 - Região do médio Tietê: esquema das relações entre as Formações Itu, Capivari e Tatuí: A. ocorrência marinha de Araçoiaba. C. ocorrência marinha de Capivari. H. ocorrência marinha de Hortolândia. I. ocorrência marinha de Itaporanga. It. ritmito clássico de Itu

Figure 8 - Middle Tietê valley, State of S.Paulo: schematic relationships of the Itu, Capivari and Tatui formations. A. Araçoiaba marine fossil locality. C. Capivari marine fossil locality. H. Hortolândia marine fossil locality. Itaporanga marine fossil locality. It. Itu classical rythmite

\section{REFERÊNCIAS BIBLIOGRÁFICAS}

ANDRADE, S. \& SOARES, P.C. 1971. Geologia do Centro-Leste do Estado de São Paulo. Petrobrás/Desul. (Boletim 407).

BARBOSA, O. \& ALMEIDA, F.F.M. 1949. A Série Tubarão na Bacia do Rio Tietê, Estado de São Paulo. Rio de Janeiro, DNPM/DGM. 16 p. (Notas Preliminares e Estudos 48)

BARBOSA, O. \& GOMES, F.A. 1958. Pesquisa de Petróleo m Bacia do Rio Corumbataí. Rio de Janeiro, DNPM/DGM. 40 p. (Boletim 171).

DINO, R.; LIMA, M.R.; ROCHA-CAMPOS, A.C. 1987. Palinologia do varvito (Subgrupo Itararé, Neopaleozóico) da região de Itu, São Paulo. In: CONGR. BRAS. PALEONT., 10. Rio de Janeiro, 1987. Resumo... Rio de Janeiro, SBP. p. 46.

FRANÇA, A.B. 1987. Stratigraphy, Depositional Environment and Reservoir Analysis of the Itararé Group (Pennocarboniferous), Paraná basin Brazil. Cincinnati. (Tese de Doutoramento, University of Cincinnati).

FRANCA, A.B. \& POTTER, P.B. 1988. Estratigrafia, Ambiente Deposicional e Análise de Reservatório do Grupo Itararé (Pennocarbonífero) Bacia do Paraná (Parte I). Boi. Geoc. Petrobrás, 2(2/4):447-491.

FÚLFARO, V.J.; STEVAUX, J.C.; SOUZA, E.E., F; BARCELOS, J.H. 1984. A Formação Tatuí (P) no Estado de São Paulo. In: CONGR. BRÁS. GEOL., 33. Rio de Janeiro, 1984. Anais... Rio de Janeiro, SBG. v. 2 , p. 711-724.

LIMA, M.R.; SAAD, A.R.; CARVALHO, R.G.; SANTOS, PR. 1976. Foraminíferos arenáceos e outros fósseis do Subgrupo Itararé (Neopaleozóico) Bacia do Paraná, São Paulo, Brasil. In: CONGR. BRÁS. GEOL., 29. Belo Horizonte, 1976. Anais... Belo Horizonte, SBG. p. 49-63.

LIMA, M.R.; DINO, R.; YOKOYA, N.S. 1983. Palinologia de concreções calcíferas do Subgrupo Itararé (Neopaleozóico da Bacia do Paraná) da região de Araçoiaba da Serra Estado de São Paulo. Anais Acad. bras. Cienc. 35(2): 195-208.

NIAKAS, S. 1986. Estudos Geofisicos Integrados à Geologia da Bacia Hidrográfica do Baixo Rio Capivari, SP (Subgrupo Itararé e intrusivas associadas). São Paulo. (Tese de Doutoramento, IG/USP)

MASSOLI, M. 1991. Relação Entre o Embasamento Cristalino e os Sedimentos Basais do Subgrupo Itararé na Região de Sorocaba-Salto de Pirapora, SP. São Paulo. (Dissertação de Mestrado, IG/USP).

MENDES, J.C. 1952. Fáunula Pennocarbonifera Marinha de Capivari, Estado de São Paulo. Suo Paulo, USP/FFLCH. p. 1-17 (Boletim Geologia 7).

MEZZALIRA, S. 1969. Geologia de subsuperfície em Itu, SP. Ocorrência de "roche moutonnée" nos testemunhos de sondagem. Anais Acad. bras. Cienc., 4(1):83-89.
MEZZALIRA, S. 1972. "Bloco errático" de grande porte na região de Sumaré - Monte Mor, Estado de São Paulo. Anais Acad. bras. Cienc., 44(2):251-257

MEZZALIRA, S. 1980. Contribuição à Geologia de subsuperfície e à paleontologia do Grupo Tubarão no Estado de São Paulo. Rev. SMA/IG $\mathbf{l}(2): 39-47$

PERINOTTO, J. A.J. 1987. Análise Estratigráfica da Seqüência Portadora de Carvão na Região de Cerquilho (SP). São Paulo. (Dissertação de Mestrado, IG/USP)

PETRI, S. 1964. Grupo Tubarão. In: Geologia do Estado de São Paulo. São Paulo, IGG. p. 56-63. (Boletim 41).

PETRI, S. 1985. Ritmitos de Itu. In: SIMP. REG. GEOL., 5. São Paulo, 1985. Atas... São Paulo, SBG/NSP. v. 1, p. 235-241.

PETRI, S. 1986. Notas adicionais sobre os ritmitos de Itu. Rev. SMA/IG, $7(1 / 2): 31-34$

PETRI, S. 1992. Litofácies e significado paleoambiental dos sedimentos Itararé na região Capivari-Rafard, Estado de São Paulo. Rev. SMA/IG, 13(1):7-30.

PIRES.F.A. \& PETRI, S. 1991. OSubgrupo Itararé na região Capivari-Rafard, Estado de São Paulo. In: SIMP. REG. GEOL. SUDESTE, 2. São Paulo, 1991. Ato... São Paulo, SBG/NSP. p. 391-396.

ROCHA-CAMPOS, A.C. 1966. Novas ocorrências de fósseis marinhos no Grupo Tubarão em São Paulo e Santa Catarina. Boi. SBG, 15(4):5-13.

ROCHA-CAMPOS, A.C.; ERNESTO, M.; SUNDARAN, D. 1981. Geological, palynological and paleomagnetic investigation on Late Paleozoic varvites from the Paraná Basin. In: SIMP. REG. GEOL., 3. São Paulo, 1981. Atas... São Paulo, SBG/NSP. v. 2, p. 162-175.

ROCHA-CAMPOS, A.C. \& RÖSLER, O. 1978. Late Paleozoic fauna! and floral successions in the Paraná basin, Southeastern Brazil. Bol. IG/USP, 9:1-16.

ROCHA-CAMPOS, A.C. \& SUNDARAN, D. 1981. Geological and palynological observation on Late Paleozoic varvites from the Itararé Subgroup, Paraná Basin, Brazil. In: CONG. LATINOAMER. PALEONT., 2. Anais. p. $257-275$.

SAAD, A.R. 1977. Estratigrafia do Subgrupo Itararé no Centro e Sul do Estado de São Paulo. São Paulo. (Dissertação de Mestrado, IG/USP).

SANTOS, PR. 1979. Distribuição Estratigráfica, Características e Fades de Diamicíitos e Rochas Associadas do Subgrupo Itararé no Centro e Sul do Estado de São Paulo. São Paulo. (Dissertação de Mestrado, IG/USP). 
SOARES, P.C. \& LANDIM, P.M.B. 1973. Aspectos regionais da estratigrafia da Bacia do Paraná no seu flanco nordeste. In: CONGR. BRAS. GEOL., 27. Aracaju, 1973. Anais... Aracaju, SBG. v. 1, p. 243-256.

SOARES, P.C.; LANDIM, P.M.B.; SINELLI, O.; WERNICK, E.; FU-TAI, W FIORI, A.P. 1977. Associações litológicas do Subgrupo Itararé e sua interpretação ambiental. Rev. Bras. Geoc., 7(2):131-149.

SOUZA, E.E., F* 1986. Mapeamento Faciológico do Subgrupo Itararé na Quadrícula de Campinas (SP). São Paulo. (Dissertação de Mestrado, IG/USP).

SOUZA, E.E., Fº \& STEVAUX, J.C. 1984. Estudo hidrogeológico do Grupo Tubarão na bacia hidrográfica do rio Capivari. In: Geologia. $2^{\circ}$ Reunião de Avaliação de Resultados do Programa para Água Subterrânea. São Paulo, FAPESP. (Relatório inédito).
STEVAUX, J.C.; SOUZA E.E., F»; TEIXEIRA, J.A.; LANDIM, P.M.B. 1987. Sistemas deposicionais do Subgrupo Itararé (P-C) na bacia hidrográfica do baixo Rio Capivari (SP): um modelo para prospecção de água subterrânea. In: SIMP. REG. GEOL., 6. Rio Claro, 1987. Atas... Rio Claro, SBG/ NSP. v. 1, p. 355-374.

SUGUIO, K. 1992. Dicionário de Geologia Marinha. São Paulo, T.A. Queiroz. 171 p.

MANUSCRITO A718 Recebido em 26 de fevereiro de 1992 Revisão do autor em 10 de maio de 1992 Revisão aceita em 29 de junho de 1992 